\title{
Study on the Existing Problems and Development Control Countermeasures of Urban Rail Transit
}

\author{
Xiaoran Wang \\ Jilin Railway Technology College, Jilin, China
}

Keywords: existing problems, development control countermeasures, urban rail transit

\begin{abstract}
With the continuous development of society, people attach great importance to urban transportation. However, in the process of continuous development of the city, the corresponding traffic is also crowded. In response to this, urban traffic needs to be comprehensively researched, and the urban traffic itself must be solved by the orbit. Although urban railroad tracks can effectively reduce the crowding phenomenon in the transportation process, there are still some problems in the process of development. In order to do this, comprehensive research is needed on the problems, and reasonable solutions are proposed based on the research results.
\end{abstract}

\section{Introduction}

At present, China's urbanization is in a period of rapid development, and the concentration of megacities continues to increase, leading to an ever-increasing scale of cities. Practice shows that as an important part of urban public transportation, urban rail transit has the advantages of large capacity, punctuality, safety, high efficiency, low carbon and environmental protection, to optimize urban spatial layout structure, cope with urban traffic congestion, and promote urban health and sustainable development. The important role is the focus of the development of China's big cities in the current and future period. In the past 10 years, urban rail transit is experiencing an unprecedented period of vigorous development, both in terms of construction scale and construction speed.

In the process of rapid development, China's urban rail transit has made remarkable achievements, such as: System technology has been greatly developed, and various standards and systems have been applied; Design and construction levels have ranked among the world's top; Equipment manufacturing industry has flourished and entered The period of self-development; the diversification of management systems and investment and financing models; the general consideration of security issues; the strengthening of basic work; However, urban rail transit has also exposed some problems in the development process, which requires further research and improvement. This article will focus on the main problems and countermeasures.

\section{Problems in Urban Rail Transit in China}

Due to the relatively late start of urban rail transit in China and the lack of corresponding laws and regulations for support, it is also relatively backward in terms of technology. Therefore, there are inevitably many problems in urban rail transit in China. China's urban rail transit construction has the following characteristics: large construction scale, long construction period, large investment volume and high technical requirements. China's urban transportation track network is generally several hundred kilometers long, and involves many high-end technologies in the construction process. Such high requirements will inevitably require strong financial support. Therefore, this has increased the government's financial pressure to a certain extent. The large investment in urban rail transit and the long period of time have led to the difficulty in balancing the previous operating revenues and the increase in loan pressure. So far, apart from Hong Kong and Macao, rail transit in other cities in China has basically suffered some losses and requires government financial support. For example, in Beijing, China, a monthly pass and a series of welfare measures have been implemented, which requires strong financial support from the 
municipal government. The financing methods adopted by China's urban rail transit construction are basically "loans + government investment", and this financing method will inevitably form the characteristics of China's urban rail transit with high debt management.

The actual passenger flow has a large deviation from the predicted passenger flow result. Urban rail transit tends to be planned and constructed according to the predicted passenger flow. People's prejudice against urban rail transit is basically due to the large deviation between actual passenger flow and predicted passenger flow. In the past, China's forecast of passenger flow was often based on the method of passenger flow transfer. The "four-stage method" is now widely used. However, each city in our country has different understandings of this "four-stage method", so it is different in the way of travel, the distribution of travel and the establishment of models. China's urban rail transit allocation model generally adopts some foreign data and parameters, but the travel characteristics of this country's residents and the development status of the city do not match, which is the large deviation between the predicted passenger flow and the actual passenger flow of urban rail transit in China. What you need to know is that after the operation of urban rail transit, there is no passenger flow. This is a waste of resources. There are not enough lines for passenger flow and a waste of resources. We will find that the subways in some cities are very crowded, such as Beijing, Shanghai, Nanjing and other developed cities. The subways in these cities are at the peak of the commute, and the traffic volume reaches the highest in one day. The main reason for this problem is to predict a large deviation between the passenger flow and the actual passenger flow, so that there is not enough vehicles for everyone to use.

The construction of urban rail transit in China is not consistent with urban land use. Urban rail transit and urban land use interact and promote each other. The rapid development of urban rail transit can promote the high-density development of land to a certain extent. At the same time, various operational points and sites of urban rail transit can stimulate the rational development and utilization of land. From the perspective of the construction of urban rail transit in the past, it is obvious that the previous rail transit construction was not combined with the development and utilization of land. There was no good understanding between the two, and no benign development model was established. . For example, in order to reduce construction costs, some subway lines plan the routes near some factories. The traffic in those places is small, and they cannot meet the late return and profitability. This kind of resource waste is because urban rail transit construction and land use are not.

The problem of unreasonable planning of urban rail transit in China From the overall perspective, there is a irrational planning of urban traffic in China. In the process of planning, blindly developing large-scale urban rail transit construction, regardless of the actual needs of the city, before design Failure to do a good job in relevant research and research has led to a lack of basis for urban orbital design and lack of corresponding data support. In addition, because the government's system of urban planning management is separated, the urban rail transit lacks effective connection with other modes of transportation. For the lack of unified planning for transportation, the planning is unscientific. Due to unreasonable planning, there are often cases of design changes, which increases the difficulty of construction of the project. The level of development among cities in China varies a lot, especially in cities with low levels of economic development. When designing urban traffic tracks, transportation systems are often inaccurate, and there is no scientific and rational design of traffic according to the actual needs of market development.

Urban rail construction belongs to government project projects, and its investment is mainly undertaken by local finance, which brings a large economic burden to local finance. In order to alleviate the pressure of local finance, we can develop a variety of financing methods by expanding the financing channels of urban rail transit. Due to the relatively late development of China's market economy and the imperfect capital market, the development of market financing policies is still not perfect. There are many problems in the actual development process of the "Metro + Property" model currently existing in China. This model is only an administrative license and it is not legally protected by laws and regulations related to the actual introduction. The government has not introduced a management approach to diversified financing, and it lacks advanced management 
concepts in its operations.

\section{Countermeasures to Promote the Development of Urban Rail Transit}

At present, the construction standards of rail transit in various cities in China are based on China's national conditions, combined with the diversified conditions of local economy and geography, which have certain guiding significance for the sustainable development of urban rail transit in China. As a world's most populous country, China has a small number of cities with a population of one million. How to effectively use existing resources to promote the development of urban rail transit is a topic worthy of further study. For those cities that operate trams and trams, in order to achieve the goal of developing urban rail transit, they can apply the concept of "coordinated planning and rational layout" to the planning and construction of tram lines. For those railways that have been abandoned or have low utilization rate, they can be remodeled to replace the urban rail line with the cable. The most representative is Shanghai Rail Transit Pearl Line, which is based on the railway inner ring line.

For those cities that do not have a tram line and lack of railroads, to achieve the goal of developing rail transit, it is necessary to combine the urban development situation to construct a feasible rail transit model and determine the optimal benefits. In the initial stage of construction, urban rail transit should reflect the diversity of its construction form, but the output of any construction form follows the construction rules of all modes of rail transit. The termination point belongs to the unified standard of all kinds of rail transit in China. .

The development of domestic urban rail transit should have its own criteria, which reflects the great effect of shaping the product brand image, reducing production costs and completing work in advance. At the time of the preparation of the relevant standards, the unified vehicle and the limit are used as the benchmark. Because there are certain differences between building types, axle load, calculated load, platform length and height, line diameter and maximum slope, station layout and equipment. In the process of preparing urban rail transit standards, the principle of phased and hierarchical preparation should be adopted. It can be refined into the primary phase and the final phase, and there can be differences in the application of technical points.

Increase the economic development of rail transit, scientifically deploy urban land to select real estate, trade, manufacturing and other formats to ensure the rationality and quality of comprehensive economic development along the line, in order to promote the sustainable development of urban rail transit Reasonable application of diverse resources such as above-ground and underground resources and stations. At this stage, rail transit enterprises are usually based on operating income, and in the process of development, they are slowly moving towards diversified marketing and development fields such as real estate, property management, logistics and transportation, and tourism and tourism.

In order to promote the development of urban rail transit, rail transit construction and land use should be placed at the same level and implemented simultaneously to achieve the goal of optimizing land resource utilization efficiency. The early planning of urban rail transit construction should be given a certain degree of attention. In the planning process, coordination should be taken as the benchmark, specifically the reasonable analysis of stations, lines and road networks, and overall design. To construct the connection design, station design and network design between urban rail transit and buildings, and improve the efficiency of land resource allocation and promote the long-term development of urban rail transit by means of rational application of urban land use.

As we all know, the urban rail transit project has a large amount of capital investment in the construction process, a long construction time, a slow rate of benefit recovery and a low level of profitability. Insufficient capital investment is still the biggest obstacle to the construction of urban rail transit. Therefore, the preparation of investment policies will show great effectiveness in promoting the construction and development of urban rail transit. Specifically, we can start from the following three aspects: fund. This is the state's macro-control means for the construction and development of urban rail transit. Under the help of special funds, the sources of funds for rail transit construction are diversified and reflect stability; the second is to compile laws and 
regulations and rationally expand foreign investment channels. On the basis of effective application of foreign government loans and financial organization loans, we will expand foreign investment channels through diversified forms such as project financing, financial leasing, and asset financing, and implement the urban rail transit project construction goals. Although the complexity and risk rate of the expansion of foreign capital channels are at a relatively high level, the effectiveness of the relevant laws and regulations can still be fully reflected. For example, the preparation of special approval agreements related to urban rail transit projects, or the preparation of certain provisions into local or national laws, making them an effective guarantee for inducing foreign investment; the third is to encourage project owners to adopt multi-channel financing strategies. At this stage, a certain amount of intrinsic assets and a stable source of income are already an effective support for the overall funds of the subway and light rail companies. In order to promote the urban rail transit construction process, the engineering business should master some financing knowledge and skills, and use stocks, bonds and other financing methods to raise funds. The government should implement an incentive system, which will encourage more investors to integrate with foreign capital into the construction process. The idle funds integrated during this period will also contribute to the construction of rail transit infrastructure. At the same time, the rational application of the rights along the line to achieve the goal of increasing the source of funds, such as the rational development and marketing of land along the rail transit project, through the form of land appreciation to obtain economic benefits.

\section{Conclusion}

All in all, with the continuous improvement of China's urbanization level, the urban population is increasing, which brings great operational pressure to traffic and serious traffic congestion. In order to alleviate traffic pressure, all cities in China are actively developing urban rail transit. However, there are many problems in the process of development, the planning is unreasonable, the financing channels are single, the construction scale is large, the speed is fast, and the management level is low. Therefore, the relevant departments should propose corresponding solutions according to the existing problems and continuously improve the development of urban rail transit in China.

\section{Acknowledgement}

The thesis is the result of the Higher education research project of JiLin Provincial Association of Higher Education in 2018, "Research on the construction of Practice training base for Urban Rail Transit based on Regional Sharing" (project number: JGJX2018D541)

\section{References}

[1] Bian Yandong, Yang Yongping. Key Issues for Sustainable and Healthy Development of Urban Rail Transit [J].Urban Rapid Transit Traffic, 2012(2):13-13.

[2] Li Xiao. Discussion on the Development Strategy of Urban Rail Transit in China during the Twelfth Five-Year Plan Period [J]. Urban Rail Transit Research, 2011(8): 5-5.

[3] Yang Yongping, Bian Yandong, Zhou Xiaoqin, Ye Xiafei. The main problems and development countermeasures of urban rail transit in China [J]. Urban Rail Transit Research, 2013(10):1-6.

[4] Song Minhua, Du Xinyan. Special Task for Helping Innovation and Capacity Building of China Urban Rail Transit Association [J]. Urban Rail Transit. 2014(04).144

[5] Tao Tao. Research on Urban Rail Transit Legislation and Law Enforcement [J]. Comprehensive Transportation.2015 (02).156 